\title{
Interaction of Collagen with the Lipids of
}

\section{Tendon Xanthomata}

\author{
Alan R. Tall, Donald M. Small, and Robert S. Lees, Biophysics Section, \\ Division of Medicine, Boston University, School of Medicine, Boston, \\ Massachusetts 02118, and the Arteriosclerosis Center, Massachusetts \\ Institute of Technology, Cambridge, Massachusetts 02139
}

A B S TRACT To determine the physical state of lipids in tendon xanthomata, six specimens surgically removed from three patients with familial hypercholesterolemia were studied by microscopy, calorimetry, and X-ray diffraction. The major constituents of the xanthomata were lipid ( $33 \%$ of dry weight) and collagen (24\% of dry weight). The principal lipids were cholesterol ester and cholesterol. Light microscopy and thin-section electron microscopy showed occasional clusters of foam cells separated by masses of extracellular collagen. Polarized light microscopy of fresh, minced tissue showed rare droplets of free cholesterol ester. When heated, the tissue shrank abruptly at $\cong 70^{\circ} \mathrm{C}$ and, consequently, a large amount of cholesterol ester was released. Scanning calorimetry of fresh pieces of xanthoma showed a single, broad, reversible liquid crystalline transition of cholesterol ester with peak temperature from 32 to $38^{\circ} \mathrm{C}$. The enthalpy $(0.71 \pm 0.07$ $\mathrm{cal} / \mathrm{g}$ ) was reduced compared with the isolated cholesterol ester from each xanthoma $(1.1 \pm 0.01 \mathrm{cal} / \mathrm{g})$. There was a large irreversible collagen denaturation endotherm (peak temperature $=67^{\circ} \mathrm{C}$; enthalpy $9.9 \mathrm{cal} / \mathrm{g}$ collagen) that corresponded to the tissue shrinkage noted by microscopy. After the collagen denaturation, the sample displayed double-peaked reversible liquid crystalline transitions of cholesterol ester, of enthalpy $1.18 \pm 0.1 \mathrm{cal} / \mathrm{g}$, that were identical to transitions of isolated cholesterol ester.

A preliminary report of part of this work was presented to the 50th Annual Scientific meeting of the American Heart Association in Miami, Fla. and was published in abstract form in 1977. Circulation. 56: III-187.

Alan Tall was a fellow of the Medical Foundation Inc. Boston, Massachusetts during the course of this work. His current address is Department of Medicine, College of Physicians \& Surgeons of Columbia University, The Presbyterian Hospital, New York 10032.

Received for publication 30 December 1977 and in revised form 2 June 1978.
Fibers dissected from xanthomata were examined by X-ray diffraction at temperatures below and above the cholesterol ester transition. At $20^{\circ} \mathrm{C}$ there was a weakly oriented equatorial reflection of Bragg spacing $36 \AA$, which corresponded to the smectic phase of cholesterol ester, and a series of oriented collagen reflections. At $42^{\circ} \mathrm{C}$ the cholesterol ester reflection disappeared. Stretched fibers examined at $10^{\circ} \mathrm{C}$ showed good orientation of collagen and cholesterol ester reflections and, in addition, meridional spacings which indicated oriented crystallization of cholesterol ester. These studies suggest that a major component of tendon xanthomata is extracellular cholesterol ester which displays altered melting and molecular orientation as a result of an interaction with collagen. At xanthoma temperatures, the cholesterol ester is in a smectic liquid crystalline state, probably layered between collagen fibrils, with the long axis of the cholesterol ester molecules perpendicular to the axis of the collagen fiber. Such collagen-cholesterol ester interactions may favor the extracellular deposition of cholesterol ester derived either from intracellular sources or directly from plasma lipoproteins.

\section{INTRODUCTION}

Tendon xanthomata are deposits of lipid and connective tissue commonly found in patients with familial hypercholesterolemia. They display slow growth and regression, tending to parallel the degree of hyperlipidemia. These deposits show some similarities to atherosclerotic plaques, both chemically and structurally. Thus, cholesterol and cholesterol ester are their main lipid components $(1,2)$ and they contain large amounts of connective tissue and clusters of cells filled with lipid droplets (3) which resemble the foam cells of fatty streaks. Xanthomata probably do not synthesize significant quantities of cholesterol but derive this lipid from the plasma (4). After intravenous injec- 
tion of radioactive cholesterol, there is a gradual rise in xanthoma cholesterol specific activity which indicates slow uptake or exchange of cholesterol with the plasma compartment $(5,6)$.

Recently, the physical state of lipids in atherosclerotic tissue (7-9), in the spleen from a patient with Tangier disease (10), and in the plasma lipoproteins (11-13) has been investigated with techniques such as polarized light microscopy, scanning calorimetry, and X-ray diffraction. These procedures permit fresh, whole tissue to be examined, and give information about the structure and interactions of lipid under physiological conditions.

With similar techniques we have now undertaken a study of tendon xanthomata, in an attempt to define the structure of the lipid deposits and possible interactions with other tissue components.

\section{METHODS}

Patients. Three patients with severe, familial hypercholesterolemia had tendon xanthomata removed because the xanthomata were causing discomfort and had failed to respond to medical treatment.

Patient A was a 36-yr-old white woman who had developed tendon xanthomata at age $13 \mathrm{yr}$ and had experienced an acute myocardial infarction at age $19 \mathrm{yr}$. During the previous $10 \mathrm{yr}$ her plasma cholesterol was $300-400 \mathrm{mg} / 100 \mathrm{ml}$, with low density lipoprotein (LDL) ${ }^{1}$ cholesterol $250-280 \mathrm{mg} / 100 \mathrm{ml}$, very low density lipoprotein (VLDL) cholesterol 20-30 $\mathrm{mg} / 100 \mathrm{ml}$, and high density lipoprotein (HDL) cholesterol about $25 \mathrm{mg} / 100 \mathrm{ml}$. At different times she had been treated with nicotinic acid, cholestyramine, neomycin, and $\beta$-sitosterol, and had undergone ileal by-pass surgery at age $24 \mathrm{yr}$. Although partially successful, none of these treatments had reduced her plasma cholesterol to below $300 \mathrm{mg} / 100 \mathrm{ml}$. Tendon xanthomata were removed from both elbows and from the extensor tendon of her right fourth finger.

Patient B was a 30-yr-old black man with a 7-yr history of tendon xanthomatosis and hyperlipidemia. During this period his total plasma cholesterol was $300-400 \mathrm{mg} / 100 \mathrm{ml}$, with LDL cholesterol $240-290 \mathrm{mg} / 100 \mathrm{ml}$, VLDL cholesterol 25-40 mg/100 ml, and HDL cholesterol $25-35 \mathrm{mg} / 100 \mathrm{ml}$. He had never followed dietary or drug treatment. A xanthoma was removed from his right elbow.

Patient $\mathrm{C}$ was a 56-yr-old white woman with hyperlipidemia and tendon xanthomatosis of at least $15 \mathrm{yr}$ duration. During the previous 6 yr her plasma cholesterol was 250-350 $\mathrm{mg} / 100 \mathrm{ml}$ with normal triglyceride, LDL cholesterol 190 230, VLDL cholesterol 40-60, and HDL cholesterol 35-40 $\mathrm{mg} / 100 \mathrm{ml}$. She had not adhered to dietary or drug treatment. Tendon xanthomata were removed from the extensor tendon of her right second finger and from her left patellar tendon. In all cases the xanthomata were wrapped in saline-soaked gauze and examined by different techniques within 2-3 h after surgical removal. The samples were not cooled below $25^{\circ} \mathrm{C}$ and, except for specimens examined by standard light and electron microscopy, were analyzed without fixation.

Bovine tendon collagen was purchasd from Sigma Chemical Co., St. Louis, Mo.

${ }^{1}$ Abbreviations used in this paper: $\mathrm{CE}$, cholesterol ester(s); HDL, high density lipoprotein; LDL, low density lipoprotein; VLDL, very low density lipoprotein.

\section{Chemical methods}

Thin-layer chromatography. Lipids from homogenates of xanthomata were doubly extracted in $10 \mathrm{vol}$ of chloroform: methanol (2:1 vol/vol), after which a Folch procedure (14) was carried out. Quantitative thin-layer chromatography was used to measure the free cholesterol, fatty acid, triglyceride, cholesterol ester, lysolecithin, sphingomyelin, and lecithin according to the method of Downing (15), as modified by Katz et al. (8). Cholesterol ester was isolated from the xanthoma lipids by preparative thin layer chromatography, with a hexane:ether (94:6 vol/vol) solvent system. Cholesterol ester spots were scraped and the silica removed by eluting the lipid with chloroform:methanol $(2: 1 \mathrm{vol} / \mathrm{vol})$ through a sintered glass funnel.

Gas-liquid chromatography. Cholesterol esters were hydrolyzed in $2 \%$ alcoholic $\mathrm{KOH}$, according to the method of Albrink (16) as modified by Smith and Slater (17).

Amino acid analysis. The delipidated xanthomata were hydrolyzed with $6 \mathrm{~N} \mathrm{HCl}$ in sealed glass vials, under $\mathrm{N}_{2}$ at $110^{\circ} \mathrm{C}$, for $24 \mathrm{~h}$, and amino acid composition was determined with a Technicon amino acid AutoAnalyzer (Technicon Instruments Corp., Tarrytown, N. Y.), according to the method of Hamilton (18). Hydroxyproline content of the hydrolysates was also determined by the method of Bergmann and Loxley (19).

Light and electron microscopy. For preparation of thin section electron micrographs, fresh samples were fixed in glutaraldehyde/paraformaldehyde within $10 \mathrm{~min}$ of excision from the patients, washed in $\mathrm{Na}$ cacodylate, fixed in $\mathrm{OsO}_{4}$, washed in distilled water, dehydrated with acetone, embedded in Epon (Shell Chemical Co., Houston, Tex.), and sectioned with a glass knife (20). Sections were stained with $\mathrm{Pb}$ citrate and post-stained with uranyl acetate (21). Sections were examined with an AEI-6B electron microscope (AEI Scientific Apparatus Inc., Elmsford, N. Y.) calibrated with a catalase standard. All samples were also sectioned and stained with hematoxylin and eosin for conventional light microscopy.

Homogenization experiments. Xanthoma was cut into small pieces and homogenized in $0.15 \mathrm{M} \mathrm{NaCl}$, with a VirTis homogenizer (VirTis Co., Inc., Gardiner, N. Y.) at a setting of 5,000 rpm for about $2 \mathrm{~min}$. The homogenates were centrifuged for $1 \mathrm{~h}$ at $40,000 \mathrm{rpm}$ in a Beckman 40.3 rotor (Beckman Instruments, Inc., Spinco Div., Palo Alto, Calif.), and the top, middle, and bottom $2 \mathrm{ml}$ of each tube were analyzed for lipid.

\section{Physical methods}

Polarized light microscopy. A Zeiss standard NL microscope (Carl Zeiss, Inc., New York) fitted with a heating and cooling stage was used to identify the physical states of lipids in fresh, minced xanthomata. Samples were initially examined at $25^{\circ} \mathrm{C}$ and then heated or cooled at $2-3^{\circ} \mathrm{C} / \mathrm{min}$. Liquid crystalline cholesterol ester ${ }^{2}$ was identified from its characteristic reversible liquid crystalline transitions between 30 and $40^{\circ} \mathrm{C}$ (22). The smectic phase was identified from its positive sign of birefringence and the cholesteric phase from its negative

${ }^{2}$ In the smectic liquid crystalline state there is a twodimensional ordering of CE molecules into layers $36 \AA$ apart, with the long axes of the $\mathrm{CE}$ molecules aligned. In the nematic liquid crystalline state, the long axes of the CE molecules are aligned but there is no layering of molecules. The cholesteric is a particular form of the nematic state, in which successive planes of CE molecules are aligned at slightly different angles, so that the planes form a screw or twist, of periodicity $\cong 4,000 \AA$. 
sign. Cholesterol monohydrate was identified as plate crystals with a characteristic angle of $79^{\circ}(8)$.

Differential scanning calorimetry. Pieces of fresh xanthoma were minced with a scalpel on a glass slide, transferred into 75- $\mu$ l stainless steel pans, and examined with a Perkin-Elmer DSC-2 differential scanning calorimeter (Perkin-Elmer Corp., Norwalk, Conn.). Samples were heated at $5^{\circ} \mathrm{C} / \mathrm{min}$ and cooled at 5,10 , or $20^{\circ} \mathrm{C} / \mathrm{min}$. The area enclosed by the transition endotherm and the base line, in conjunction with the mass of material in the sample pan, the instrumental sensitivity, and a calibration factor was used to calculate the transition enthalpy. Enthalpy and temperature were calibrated as described previously (23). Each sample was scanned a number of times in the temperature range of interest and multiple samples (three to five) were examined from each specimen.

$X$-ray diffraction. 1- to 3-cm fibers were dissected with fine scissors from the cut surface of xanthomata. In some instances unstretched fibers were placed in sealed Lindeman glass tubes (Lindeman Corp., Indianapolis, Ind.) and examined immediately after removal from the patient. However, better orientation of diffracted $X$ rays was obtained with fibers that had been aligned by being stretched with a small weight (about $50 \mathrm{~g}$ ) for about $24 \mathrm{~h}$. The aligned fibers were examined while still under tension. $\mathrm{X}$-ray diffraction studies were performed with nickel-filtered $\mathrm{CuK} \alpha$ radiation from an Elliot GX6 rotating anode generator (Baird and Tatlock, London, England) and Elliot toroidal (Baird and Tatlock) or Franks mirror optics as described previously (11).

Results are expressed as mean \pm SEM. Significance of differences between means was determined by Student's $t$ test.

\section{RESULTS}

Compositional analysis: lipid analysis. The tissue dry weights were $28.5-29.5 \%$ of the wet weights. Lipid constituted about $33 \%$ of the dry weight of the tissue (or $9.5 \pm 0.62 \%$ of the wet weight). The six xanthomata showed variable lipid composition (Table I) with a preponderance of cholesterol ester and cholesterol, and a paucity of phospholipid and triglyceride. Samples taken from different sites within the same xanthoma also showed some variability of lipid composition (Table I). A plot of the cholesterol, cholesterol ester, and phospholipid compositions on triangular coordinates (8) predicted the existence of separate cholesterol ester and phospholipid liquid crystalline phases in patients A and B and, in addition, a cholesterol crystal phase in patient $C$.

Cholesterol ester fatty acid analysis. To obtain enough material for analysis of fatty acid composition, samples were pooled from the different xanthomata in each patient. The cholesterol ester fatty acid composition was fairly uniform, and showed a relatively high content of saturated and monounsaturated fatty acids, and a low content of cholesterol linoleate compared, for example, to plasma LDL (11) or atherosclerotic fibrous plaques (17) (Table II).

Amino acid analysis. The material left after extraction of lipid from the xanthomas was hydrolyzed in $\mathrm{HCl}$ and subjected to amino acid analysis (Table III). Amino acids constituted $58 \pm 3.4 \%$ of the chloroform: methanol insoluble residue, or $39 \%$ of the dry weight. The amino acid composition was notable for a high content of hydroxyproline (7\%) and glycine (25\%), which indicates that collagen was the major protein constituent of the xanthomas. Assuming an $11 \%$ content of hydroxyproline in the tendon xanthoma collagen (based on the hydroxyproline content of tendon collagen), collagen constituted $36 \pm 1.5 \%$ of the nonlipid content of the xanthomas, or $24 \%$ of the dry weight. Direct analysis for hydroxyproline, with the method of Bergmann and Loxley (19) gave a value of $38.5 \pm 1.8 \%$.

TABLE I

Lipid Composition (\%) of Xanthomata*

\begin{tabular}{cccccccc}
\hline Patient & Site & Cholesterol & Triglyceride & CE & Lysolecithin & Sphingomyelin & Lecithin \\
\hline A & Right & 14 & 1 & 70.8 & 0 & 4.3 & 9.5 \\
& elbow & 11 & 0.2 & 74.8 & 1 & 5.2 & 8.1 \\
& Left & 11 & 0.2 & 79 & 0.5 & 4.3 & 5 \\
& elbow & 9 & 1 & 75 & 1.5 & 4.3 & 9 \\
& Finger & 16.1 & - & 71.2 & - & 4.8 & 7.8 \\
& B & 7.1 & 3.0 & 80.5 & 0.25 & 3.5 & 4 \\
& & 9.9 & 1.8 & 80.8 & 0.35 & 3.7 & 5.0 \\
C & Knee & 42 & 6.5 & 38 & 2.5 & 4.5 & 8 \\
& & 34 & 5.4 & 46 & 1.3 & 5.5 & 7.3 \\
& Finger & 50 & 8 & 26 & - & 4.4 & 11 \\
& & 22 & 7.4 & 46 & & 4.4 & 19 \\
\hline
\end{tabular}

* Lipids were analysed by double Folch (14) extraction and quantitative thin-layer chromatography (15). Results of duplicate samplings from different sites in the xanthomata are shown. 
TABLE II

CE Fatty Acids (\%) of Xanthomata

\begin{tabular}{|c|c|c|c|c|c|c|c|c|c|c|c|c|c|c|c|}
\hline Patient & $14: 0$ & $16: 0$ & $16: 1$ & $18: 0$ & $18: 1$ & $18: 2$ & $18: 3(\omega 3)$ & $20: 2$ & $20: 3(\omega 9)$ & $20: 4$ & $22: 4$ & $22: 5(\omega 6)$ & $22: 5(\omega 3)$ & $22: 6(\omega 3)$ & other \\
\hline A & 0.8 & 9.0 & 6.5 & 2.1 & 50.9 & 19.2 & 1.4 & 1.6 & 2.6 & 3.2 & 0.9 & 0.5 & 0.3 & 0.4 & 0.7 \\
\hline B & 0.8 & 7.3 & 6.8 & 1.0 & 50.4 & 17.6 & 2.0 & 2.4 & 3.2 & 4.0 & 1.3 & 0.5 & 0.5 & 0.4 & 1.8 \\
\hline C & 0.5 & 11.7 & 0.7 & 0.8 & 42.3 & 23.3 & 1.7 & 2.0 & 3.8 & 6.2 & 2.1 & 0.6 & 0.0 & 0.8 & 2.2 \\
\hline
\end{tabular}

Compared with collagen, the total amino acid content of the xanthomas was slightly enriched in acidic amino acids.

Centrifugation of homogenized xanthoma. When homogenized xanthoma was subjected to preparative ultracentrifugation, about $50 \%$ of the lipid formed a floating skin while $50 \%$ remained in the pellet. The composition of the lipid skin was cholesterol $3.9 \%$, triglyceride $0.1 \%$, cholesterol ester $93.8 \%$, sphingomyelin $1.3 \%$, and lecithin $0.9 \%$; while the pellet contained cholesterol $13.6 \%$, cholesterol ester $74.1 \%$, lysolecithin $0.4 \%$, sphingomyelin $5.2 \%$, and lecithin $6.8 \%$. The amount of cholesterol ester liberated from the tissue depended upon the time and vigor of homogenization. Thus, when the pellet formed from a first centrifugation was homogenized and centrifuged a second time, it liberated an equal proportion of its cholesterol ester. These results suggest that the homogenization procedure per se liberated cholesterol ester from the tissue.

Light microscopy. Sections stained with haematoxylin and eosin showed a few clusters of cells with foamy cytoplasm which resembled foam cells (the cell membranes represent the phospholipid liquid crystals predicted from lipid composition). In most areas of the tissue the cells were interspersed with thick bands of connective tissue.

Electron microscopy. Two of the three xanthomas from patient $A$, and the xanthoma from patient $B$, were examined by thin section electron microscopy. The principal constituent of all the specimens was bundles of fibrillar material (Fig. 1), which at high magnification was identified as collagen from its characteristic $620 \pm 12 \AA$ periodicity $(n=13$ micrographs). The mean diameter of the collagen fibrils was $455 \pm 20 \AA$, and although the space between fibrils ranged between 0 and $2,000 \AA$, the average distance was about $250 \AA$. All sections were remarkable for a paucity of large lipid droplets or cellular elements.

Polarized light microscopy. Examination of pieces of minced tissue at $25^{\circ} \mathrm{C}$ showed occasional smectic liquid crystals of free cholesterol ester and, also, in patient $\mathrm{C}$, crystals of free cholesterol. The amorphous bulk of the tissue showed a diffuse background birefringence, which underwent no changes when cooled from $25^{\circ} \mathrm{C}$ to $10^{\circ} \mathrm{C}$ or subsequent heating to $60^{\circ} \mathrm{C}$. When heated further, there was an abrupt shrinkage of the tissue, associated with separation of an oily phase, most evident at about $70^{\circ} \mathrm{C}$. When cooled to $20^{\circ} \mathrm{C}$, the oily material was identified as cholesterol ester which displayed characteristic reversible liquid crystalline transitions (22). In all three xanthomata of patient $\mathrm{A}$, the smectic to cholesteric transitions occurred at $34^{\circ} \mathrm{C}$, and the cholesteric to isotropic liquid transition at $37-38^{\circ} \mathrm{C}$, while in patient $\mathrm{B}$ the respective temperatures were 37 and $41^{\circ} \mathrm{C}$ (Table IV). In patient $\mathrm{C}$, both xanthomata showed a smectic-disordered transition at about $31^{\circ} \mathrm{C}$, but no cholesteric phase could be seen, as expected from the high triglyceride content (Table I), because triglyceride abolishes the optical and calorimetric properties of the cholesteric phase (11).

Differential scanning calorimetry. Examination of fresh xanthoma by differential scanning calorimetry showed a reversible thermal transition between $\cong 30$ and $45^{\circ} \mathrm{C}$, of peak temperature $36-37^{\circ} \mathrm{C}$, for patient $\mathrm{A}$, $37-38^{\circ} \mathrm{C}$ for patient $\mathrm{B}$ (Fig. 2 ), and $31-32^{\circ} \mathrm{C}$ for patient C (Table IV). The enthalpy of this transition was $0.71 \pm 0.07 \mathrm{cal} / \mathrm{g}$ cholesterol ester (13 experiments on

TABLE III

Amino Acid Composition (\%) of Tendon Xanthomata*

\begin{tabular}{lcccccccc}
\hline Hydroxylysine & Lysine & Histidine & Arginine & Cysteic acid & Hydroxyproline & Aspartic acid & Threonine & Serine \\
\hline $0.54 \pm 0.02$ & $4.3 \pm 0.26$ & $1.2 \pm 0.06$ & $5.5 \pm 0.09$ & $0.57 \pm 0.05$ & $7.12 \pm 0.4$ & $6.9 \pm 0.26$ & $3.1 \pm 0.71$ & $4.4 \pm 0.24$ \\
\hline Glutamic acid & Proline & Glycine & Alanine & Valine & Isoleucine & Leucine & Tyrosine & Phenylalanine \\
\hline $9.1 \pm 0.26$ & $9.9 \pm 0.21$ & $25.6 \pm 0.77$ & $9.6 \pm 0.27$ & $4.1 \pm 0.22$ & $2.14 \pm 0.2$ & $4.72 \pm 0.31$ & $1.48 \pm 0.1$ & $2 \pm 0.16$ \\
\hline
\end{tabular}

* Results shown are mean \pm SEM obtained from individual xanthomata $(n=6)$. 


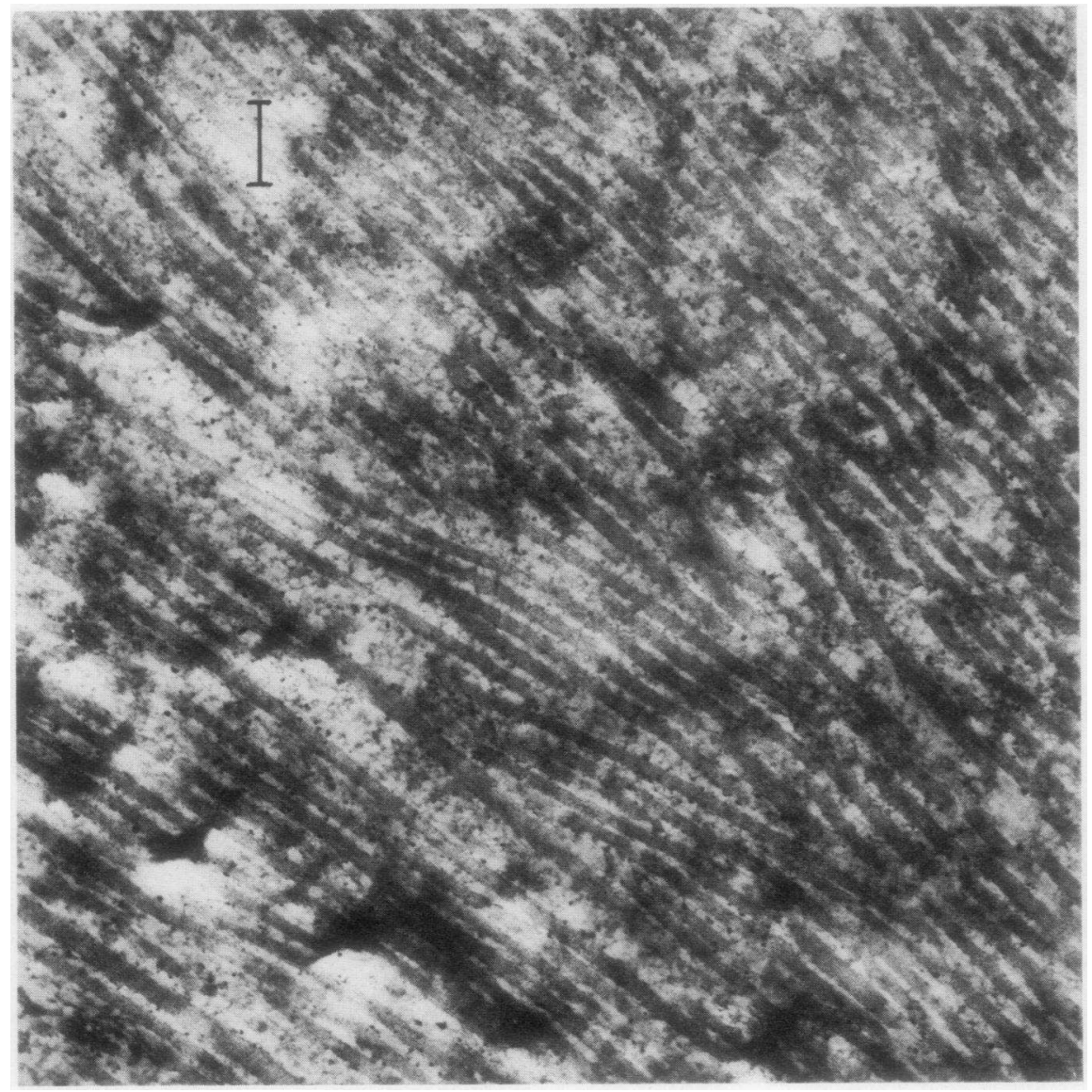

FIGURE 1 Thin section electron micrograph of xanthoma. Samples were fixed in glutaraldehyde/ paraformaldehyde immediately after removal from the patients, sectioned, and stained as described in Methods. The fibrillar material was identified as collagen from its banding pattern of periodicity $620 \AA$. The bars indicate $2,000 \AA$.

six xanthomata). When heated further, there was a large irreversible endotherm at $67 \pm 0.6^{\circ} \mathrm{C}$, of enthalpy $9.9 \pm 1.2 \mathrm{cal} / \mathrm{g}$ collagen. The mean onset and end temperatures (measured from the intersections of tangents to the transition with the base line) were 60 and $75^{\circ} \mathrm{C}$. With subsequent cooling and heating, there were reversible smectic-cholesteric and cholesteric-liquid transitions of cholesterol ester at 32 and $37^{\circ} \mathrm{C}$ in patient

TABLE IV

Temperature of CE Transitions*

\begin{tabular}{|c|c|c|c|c|c|c|}
\hline \multirow[b]{2}{*}{ Patient } & \multirow[b]{2}{*}{ Site } & \multirow{2}{*}{$\begin{array}{l}\text { Intact xanthoma } \\
\text { smectic-disordered }\end{array}$} & \multicolumn{2}{|c|}{$\begin{array}{c}\text { Xanthoma after thermal collagen } \\
\text { denaturation }\end{array}$} & \multirow[b]{2}{*}{ CE/Triglyceride } & \multirow[b]{2}{*}{$18.1 / 18.2$} \\
\hline & & & Smectic-cholesteric & Cholesteric-liquid & & \\
\hline \multirow[t]{3}{*}{$\mathbf{A}$} & Right elbow & 37 & $32-34$ & 37 & 122 & \\
\hline & Left elbow & 36 & $32-34$ & 37 & 128 & $2.64 \rrbracket$ \\
\hline & Finger & 37 & 33 & 37 & $\infty$ & \\
\hline B & Finger & 38 & $34-37$ & 41 & 33 & 2.88 \\
\hline \multirow[t]{2}{*}{$\mathrm{C}$} & Knee & 31 & $-31-\S$ & & 6.9 & $1.84 \ddagger$ \\
\hline & Finger & 32 & $-31-$ & & 4.5 & \\
\hline
\end{tabular}

* Temperatures refer to the peak temperatures noted by differential scanning calorimetry and the median melting temperature of CE droplets observed by polarized light microscopy.

\$ Average value for patient.

$\$$ In patient $C$, this was a single-peaked smectic-liquid transition. 


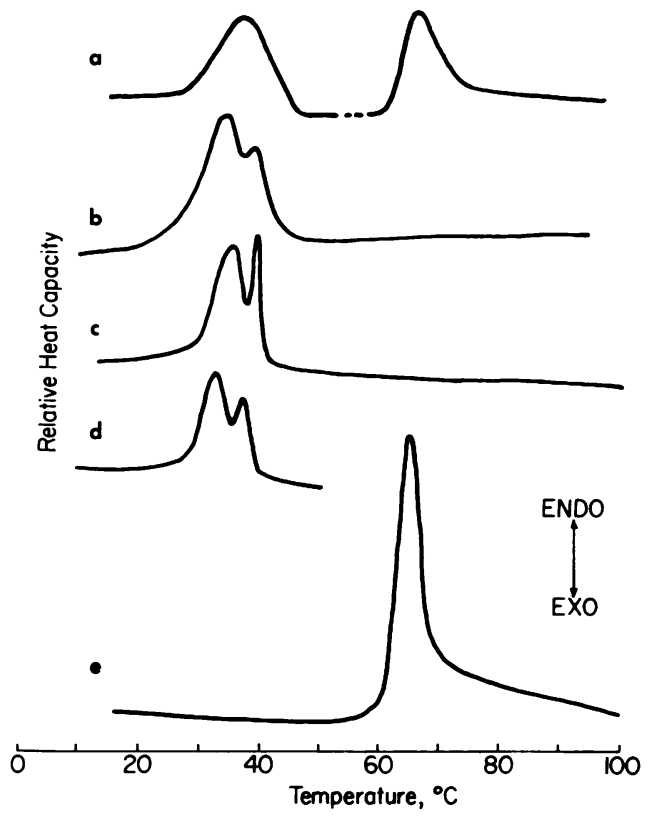

FIGURE 2 Differential scanning calorimetric heating curves of xanthoma specimens $(a)$ fresh, minced xanthoma, $(b)$ same specimen after being heated to $100^{\circ} \mathrm{C},(c) \mathrm{CE}$ isolated from xanthoma lipids, $(d)$ lipid skin formed by preparative ultracentrifugation of homogenized xanthoma, $(e)$ chloroform: methanol insoluble residue of xanthoma. All samples were heated at $5^{\circ} \mathrm{C} / \mathrm{min}$ in hermetically sealed $75-\mu l$ sample pans. Endothermic (ENDO) transitions are represented by upward deflections of the base line, and exothermic (EXO) transitions by downward deflections. In $(a)$, the scale sensitivity between 0 and $50^{\circ} \mathrm{C}$ is shown at $0.4 \mathrm{mcal} / \mathrm{s}$, and between 55 and $100^{\circ} \mathrm{C}$ at $2 \mathrm{mcal} / \mathrm{s}$ ( $\times 1 / 5$ sensitivity). Upon heating the intact xanthoma $(a)$, there is a liquid crystalline transition of CE between $25-45^{\circ} \mathrm{C}$, followed by an irreversible collagen denaturation. Upon subsequent heating $(b)$, the CE transition displays an increased enthalpy. Results shown are for patient $B$.

A, 34 and $41^{\circ} \mathrm{C}$ in patient $\mathrm{B}$ (Fig. $2 b$ ), and a single transition of peak temperature $31^{\circ} \mathrm{C}$ in patient $\mathrm{C}$. The total enthalpy of these liquid crystalline transitions of cholesterol ester of heat denatured xanthomata was $1.18 \pm 0.10 \mathrm{cal} / \mathrm{g}$ cholesterol ester which was significantly greater $(P<0.01)$ than that of intact xanthoma. Xanthoma kept for 1 mo at $-20^{\circ} \mathrm{C}$ showed an initial endotherm of peak temperature $\sim 38^{\circ} \mathrm{C}$ (patient $\mathrm{B}$ ) and enthalpy $7 \mathrm{cal} / \mathrm{g}$ cholesterol ester, which indicates that the cholesterol ester had crystallized (12). When recooled, liquid crystal transitions were observed which were similar to those of the native xanthoma. When heated further, the collagen transition was observed which indicated that although storage at $-20^{\circ} \mathrm{C}$ produced crystallization of cholesterol ester(s) $(\mathrm{CE})$, this did not alter the structure of the collagen.

Pure CE isolated from the xanthoma of patient B showed liquid crystalline transitions (Fig. 2c) at identical temperatures to the heat-denatured, intact xanthoma (Fig. 2b). When examined by differential scanning calorimetry, the lipid skin obtained by preparative ultracentrifugation of homogenized xanthomata showed sharp transitions identical to unbound or unassociated CE (Fig. 2d). Delipidated material from the xanthoma showed a sharp, irreversible transition of peak temperature $\left(68^{\circ} \mathrm{C}\right)$ and enthalpy $\cong 10 \mathrm{cal} / \mathrm{g}$ collagen, resembling the high temperature denaturation endotherm observed in the native tissue (Fig. 2e). A denaturation endotherm of identical temperature and enthalpy was obtained from a sample of bovine tendon collagen (not shown).

To determine the temperature dependence of the release of $\mathrm{CE}$ from intact xanthoma, tissue was systematically heated, cooled, and reheated to progressively higher temperatures (Fig. 3). Heating through the large, irreversible endotherm of peak temperature $67^{\circ} \mathrm{C}$ clearly resulted in a double-peaked endotherm of increased enthalpy (Fig. 3). When the increase in enthalpy of the CE transition was expressed as a function of temperature, a sigmoidal curve resulted (Fig. 4). The sigmoidal curve approximates the integrated form of the endotherm of peak temperature $67^{\circ} \mathrm{C}$, and has the same midpoint temperature $\left(67^{\circ} \mathrm{C}\right)$. Thus, the release of $\mathrm{CE}$ paralleled the thermal denaturation of collagen.

$X$-ray diffraction. The cut surface of the fresh xan-

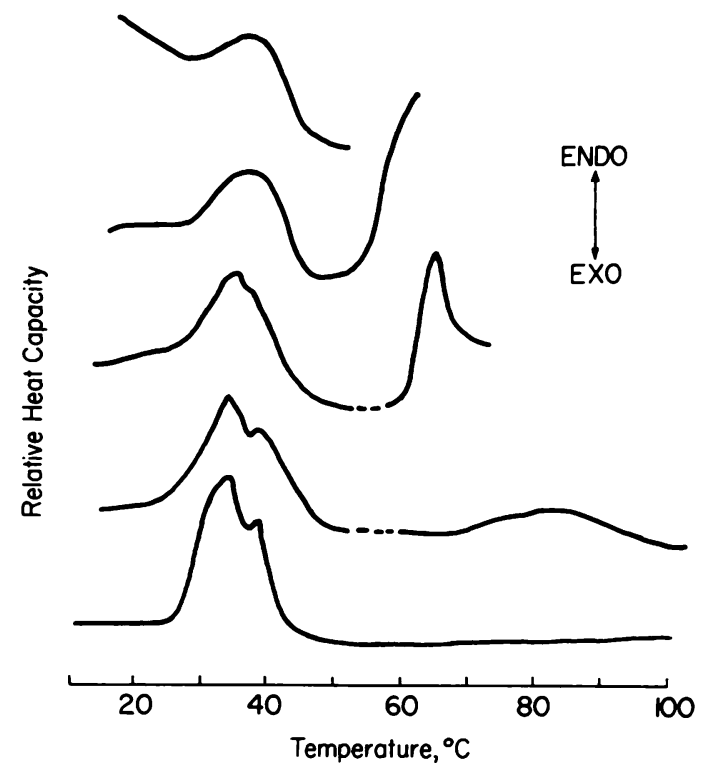

FIGURE 3 Differential scanning calorimetric heating curves of xanthoma. Xanthoma minced with a scalpel, was sealed in a 75- $\mu \mathrm{l}$ pan and then heated to $50^{\circ} \mathrm{C}$, cooled to $0^{\circ}$, (cooling not shown), heated to $60^{\circ}$, cooled to $0^{\circ}$, heated to $70^{\circ}$, cooled to $0^{\circ}$, heated to $100^{\circ}$, cooled to $0^{\circ}$, and heated to $100^{\circ} \mathrm{C}$. (Figure reads top to bottom.) The sensitivity was $0.4 \mathrm{mcal} / \mathrm{s}$, except in sections initiated by dashed lines, where the sensitivity was $2 \mathrm{mcal} / \mathrm{s}$. With heating to higher temperatures there is a progressive increase in the enthalpy of the transition between 25 and $45^{\circ} \mathrm{C}(\mathrm{CE})$, especially after the irreversible high temperature denaturation of peak temperature $67^{\circ} \mathrm{C}$ (collagen). ENDO and EXO show the direction of endothermic and exothermic transitions. 


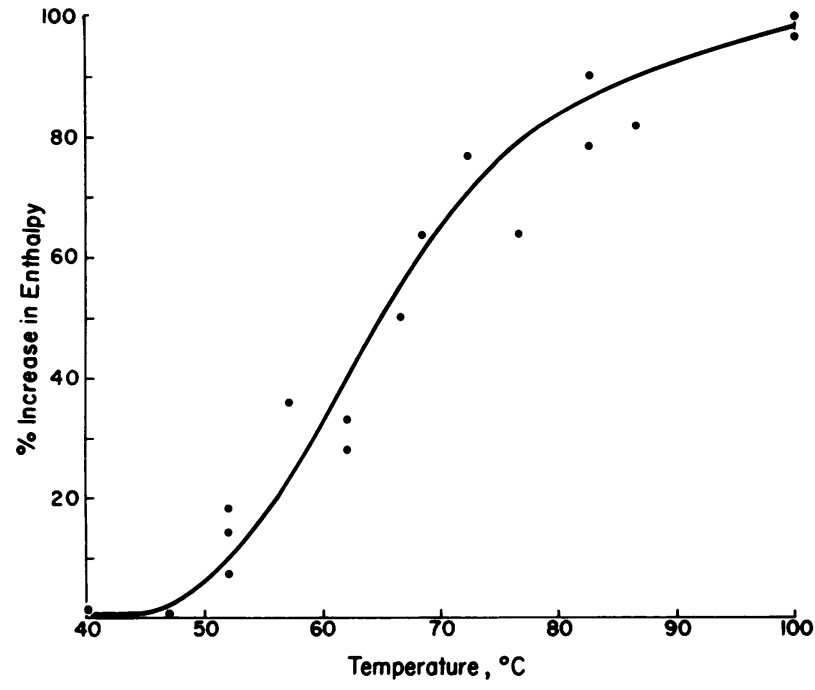

FIgure 4 The increase in enthalpy of the xanthoma CE transition as a function of temperature. The xanthoma specimens (six experiments) were heated to progressively higher temperatures and the percent increase in the enthalpy of the CE liquid crystal melt measured as a function of the temperature of the previous heating run. In each experiment, the percent increase in enthalpy was determined from the increase in area of the CE transition after heating to a certain temperature $\div$ total increase in area after heating to $100^{\circ} \mathrm{C}$. The midpoint temperature of the increase in enthalpy (i.e., the temperature at which $50 \%$ of the increase occurred) corresponded to the peak or midpoint temperature of collagen denaturation $\left(68^{\circ} \mathrm{C}\right)$, which suggests that the liberation of $\mathrm{CE}$ was a result of denaturation of collagen.

thoma consisted of a network of fibers embedded in a yellow matrix. X-ray diffraction performed on randomly selected, unoriented pieces of xanthoma immediately after removal from the patient showed a sharp diffraction fringe which corresponded to a Bragg spacing of $36 \AA$ and diffuse fringes at about $15 \AA$ and $4.8 \AA$. There were no short spacings of crystalline
CE. The 36- $\AA$ spacing, characteristic of the smectic phase of $\mathrm{CE}$, disappeared when heated to $45^{\circ} \mathrm{C}$, while the diffuse fringes persisted. The $15-\AA$ spacing is part of the diffraction pattern of collagen $(24,25)$. To obtain greater resolution, $\mathrm{X}$-ray diffraction was performed on oriented fibers.

Partially oriented, unstretched fibers, examined below the $\mathrm{CE}$ transition (e.g., at $10^{\circ} \mathrm{C}$ ) immediately after removal from the patients, showed a weakly oriented, $36-\AA$ equatorial reflection arising from smectic liquid crystalline $\mathrm{CE}$, and also a weakly oriented equatorial reflection at $15 \AA$ arising from the collagen (Fig. 5a). To improve the alignment of collagen, fibers were stretched and examined while under tension. Under these conditions well oriented equatorial reflections at 36 and $15 \AA$ were observed (Figs. $5 b$ and $c$ ). In addition, a series of meridional reflections were observed, identical in spacing to those of crystalline $\mathrm{CE}$ isolated from the xanthomata (Fig. $5 d$ ). Thus, oriented crystallization of $\mathrm{CE}$ occurred during the preparation of these specimens. When heated to temperatures above the calorimetric transition of $\mathrm{CE}$ (e.g., $42^{\circ} \mathrm{C}$ ) all of the $\mathrm{CE}$ diffractions disappeared, while the equatorial collagen spacing persisted (Fig. $5 e$ ). Examination of the low angle diffraction pattern of oriented, stretched fibers at $10^{\circ} \mathrm{C}$ showed a series of sharp, meridional reflections (Fig. $5 f$ ) which proved to be the 4th and 6th to 11th orders of the $620-\AA$ periodicity of the collagen fibril (Table V). All areas of the xanthomata examined by $\mathrm{X}$-ray diffraction showed collagen and $\mathrm{CE}$ diffractions with the relative intensities paralleling the chemical composition. Furthermore, 10 different fiber preparations showed the same orientation of $\mathrm{CE}$ with respect to the collagen fiber axis. The same patterns were observed for different sites in the same sample. In the xanthomata from patient $\mathrm{C}$, which showed cholesterol monohydrate crystals by microscopy, there were additional reflections arising from crystalline cholesterol (e.g., note the

Figure 5 X-ray diffraction of xanthoma fibers $(a)$ unstretched fiber, $10^{\circ} \mathrm{C}$ (toroidal camera), $(b)$ streched fiber, $10^{\circ} \mathrm{C}$ (toroidal camera), short exposure, $(c)$ as in $(b)$, but longer exposure, $(d)$ purified xanthoma $\mathrm{CE}$, at $10^{\circ} \mathrm{C}$, toroidal camera, $(e)$ stretched fiber, $42^{\circ} \mathrm{C}$, toroidal camera, $(f)$ stretched oriented fiber, $10^{\circ} \mathrm{C}$, Franks camera (lower angle region). All specimens are shown with the fiber axis (meridional) parallel to the length of this page. In $(a)$, there are weakly oriented equatorial reflections, which correspond to Bragg spacings of 36 and $15 \AA$, arising from smectic CE and collagen, respectively. The spotty equatorial reflections at 34 and $17 \AA$ are a result of crystalline cholesterol monohydrate. In (b), the $36-\AA$ equatorial reflection is seen as an intense fringe close to the center of the film. In addition, there are a series of meridional reflections arising from crystalline CE. In $(c)$, the orientation of the $36-\AA$ fringe is not seen because of overexposure, but the equatorial reflection from collagen at $15 \AA$ can be more clearly seen. On the original film, a $2.8-\AA$ meridional spacing arising from collagen can also be seen. All of the fringes of crystalline $\mathrm{CE}$ shown in $(d)$ can be seen on the original films of $(b)$ and $(c)$. CE of the xanthoma fibers $(b$ and $c)$ melts when heated to $42^{\circ} \mathrm{C}$, shown in $(e)$, leaving only the collagen reflections (15- $\AA$ equatorial and 2.8- $\AA$ meridional-the latter is seen on the original films). In $(f)$ is shown the low-angle meridional diffractions of collagen (orders of $630 \AA$ ) and a strong $36-\AA$ equatorial reflection arising from CE. There is also a weak $34-\AA$ reflection due to unesterified cholesterol. $(a)$ is from patient $\mathrm{C}$ and $(b-f)$ from patient $B$. 


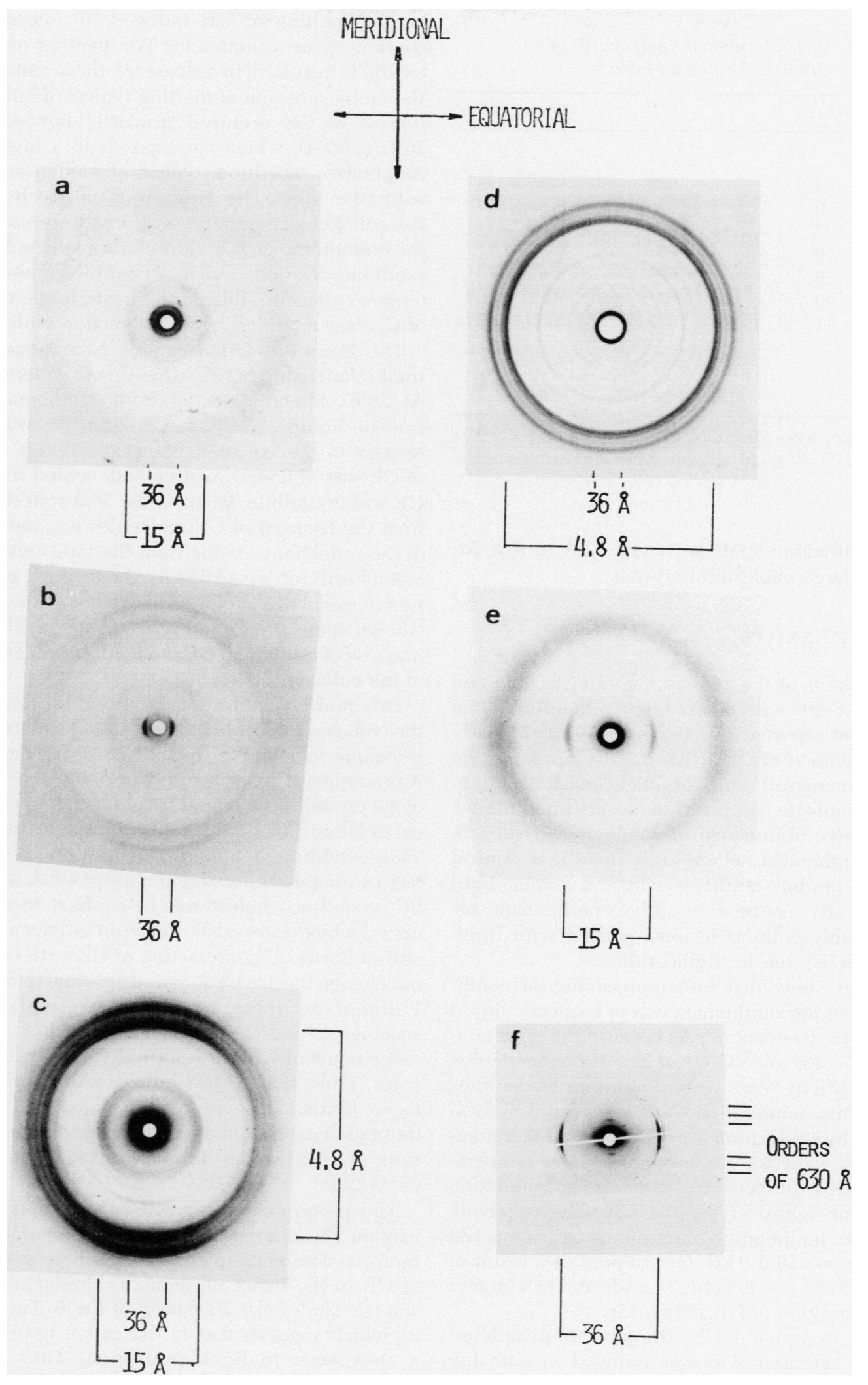


TABLE V

Low Angle Meridional Spacings (d) of Oriented Xanthoma Fiber*

\begin{tabular}{cccl}
\hline Spacing (d) & Order (n) & $\mathrm{nX} \mathrm{d}$ & Relative intensity \\
\hline$\AA$ & & $\AA$ & \\
155 & 4 & 620 & Very weak \\
106 & 6 & 636 & Strong \\
91.2 & 7 & 638 & Weak \\
78.9 & 8 & 631 & Weak \\
69.6 & 9 & 626 & Strong \\
63.5 & 10 & 634 & Weak \\
57.8 & 11 & 635 & Intermediate \\
& & mean $=631 \AA$ & \\
\cline { 2 - 3 } & & & \\
\hline
\end{tabular}

* These spacings were recorded with Franks' mirror optics at $10^{\circ} \mathrm{C}$. Orders $1-3$ could not be observed because of the backstop.

equatorial diffraction spots at 34 and $17 \AA$ in Fig. $5 a$, arising from large cholesterol crystals).

\section{DISCUSSION}

The composition of the tendon xanthomata obtained from three patients with familial hypercholesterolemia resembles that reported previously (1-3), particularly the preponderance of cholesterol and CE among the lipids, the increased ratio of cholesterol oleate to cholesterol linoleate compared to plasma lipoproteins, and the relative abundance of connective tissue (3). Tuberous xanthomata, which arise in similar clinical situations to tendon xanthomata have a similar lipid composition. By contrast, eruptive xanthomata are transient, highly cellular lesions, packed with lipidladen foam cells, rich in triglyceride.

Our studies show that under physiological conditions the CE of the xanthomata was in a smectic liquid crystalline state (see footnote 2 ) because the peak temperatures $\left(37,38\right.$, and $\left.32^{\circ} \mathrm{C}\right)$ of the $\mathrm{CE}$ smectic-disordered transitions were well above that of the sites from which the xanthomata were removed $\left(28-30^{\circ} \mathrm{C}\right.$ as measured by application of a liquid crystal thermometer to the skin surface). Indeed, the cooler temperatures of extensor surfaces may favor the accumulation of the smectic liquid crystalline $\mathrm{CE}$. The relatively high transition temperature of xanthoma $\mathrm{CE}$, compared to human plasma LDL (11), for example, is a result of an increased ratio of $C E$ to triglyceride and to a greater degree of saturation of CE fatty acids.

Compared to isolated $\mathrm{CE}$, the smectic-disordered transition of xanthoma $\mathrm{CE}$ was reduced in enthalpy (from 1.1 to $0.7 \mathrm{cal} / \mathrm{g} \mathrm{CE}$ ), which indicates constraints on the melting of $\mathrm{CE}$ induced by interaction with another tissue component. The heating of the tissue to $100^{\circ} \mathrm{C}$ resulted in release of these constraints, as shown by subsequent melting typical of bulk CE. The release of $\mathrm{CE}$ occurred primarily between 55 and $75^{\circ} \mathrm{C}$ (Fig. 4), which corresponds to a high enthalpy cooperative transition, typical of tendon collagen denaturation (26). The latter was positively identified as a collagen denaturation by the presence of an identical endotherm in the chloroform:methanol insoluble xanthoma residue, and in a control sample of bovine tendon collagen. Thus, in the fresh tissue, the melting of $\mathrm{CE}$ was modified by an interaction with collagen.

The X-ray diffraction experiments suggest a structural relationship between xanthoma collagen and CE. At $20^{\circ} \mathrm{C}$, fibers dissected from xanthomata showed smectic liquid crystalline $\mathrm{CE}$, partially oriented with respect to the collagen fiber axis. Better orientation of $\mathrm{CE}$ was obtained in stretched, cooled fibers where $\mathrm{CE}$ was crystalline. Because the $36-\AA$ reflection arising from the layering of $\mathrm{CE}$ molecules was perpendicular to the reflections arising from the long axis of the collagen fibrils (orders of $620 \AA$ ), the layering of the smectic $\mathrm{CE}$ occurs between fibrils rather than along them (shown schematically in Fig. 6). That is, the long molecular axis of individual $\mathrm{CE}$ molecules lies perpendicular to the collagen fiber axis.

Oriented crystallization (epitaxis) on the surface of the collagen molecule has been demonstrated for some inorganic salts and for organic urea derivates $(24,27)$. A prerequisite for epitaxis is that one of the dimensions of the crystalline-unit cell should bear a simple numerical relationship to the collagen layer line at $9.4 \AA$. This condition is apparently fulfilled by CE which has a strong meridional reflection at $4.8 \AA$, and perhaps by crystalline cholesterol. In contrast to the organic ureas, which intercalate between collagen molecules within fibrils (27), interaction of CE with collagen did not change the $15-\AA$ equatorial spacing of the collagen. Furthermore, there were no lower angle equatorial spacings to indicate hexagonal or other ordered arrangements of $\mathrm{CE}$ between individual collagen molecules. Thus, the CE lies between and not within collagen fibrils. This view is supported by the normal thermal denaturation of collagen and the normal thickness of collagen fibrils as seen by electron microscopy (25).

The proposed collagen/CE structure (Fig. 6) may explain the altered melting behavior of $\mathrm{CE}$ of xanthomata. The enthalpy of the single-peaked transition of $\mathrm{CE}$ in the intact xanthoma is similar to that of the smectic-cholesteric transition of the isolated CE (Fig. 2 ), which suggests that in the native tissue, CE lacks a cholesteric to liquid transition. Thus, above the transition, CE may be held in a cholesteric-like or 


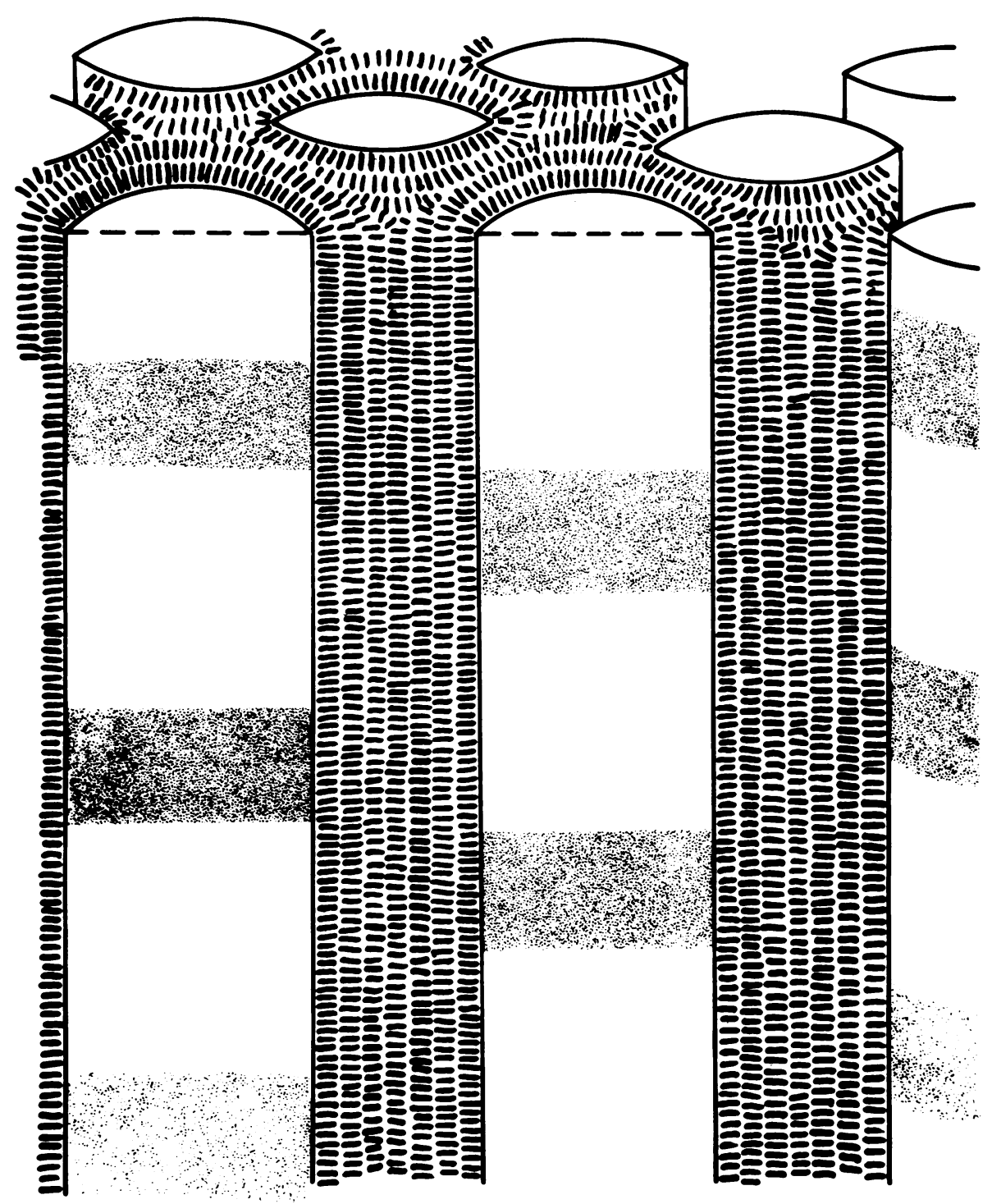

Figure 6 Model for $\mathrm{CE}$ and collagen interaction. CE is shown as - and collagen as crossbanded cylinder.

nematic state by the collagen molecule, with loss of layering between CE molecules but a persistent onedimensional alignment of their long molecular axes.

It is unlikely that $\mathrm{CE}$ of xanthomata exists within intact LDL because the chemical composition, the low phospholipid content, and the high cholesterol oleate:linoleate ratio are unlike that of plasma LDL. Furthermore, xanthomata show partially oriented CE $\mathrm{X}$-ray diffractions whereas LDL gives only unoriented $\mathrm{CE}$ reflections (11). Although we have identified an interaction between collagen and CE, we cannot exclude possible interactions of collagen or $\mathrm{CE}$ with other unidentified tissue components, for example, cholestanol esters or mucopolysaccharides.
That cholesterol and CE probably exist between and not within collagen fibrils suggests that the lipids are deposited after secretion of collagen from cells. Procollagen molecules are secreted from cells and assembled into fibrils subsequent to the action of extracellular enzymes which cleave off an $\mathbf{N H}_{2}$-terminus peptide (28). CE could be deposited onto collagen directly from LDL, perhaps because of an affinity of the hydrophobic surface of the collagen fibril for CE. Alternatively, LDL CE may be taken up, hydrolyzed, and reesterified by cells which eventually die and liberate $\mathrm{CE}$ into the extracellular space. The latter process is suggested by the altered fatty acid composition of xanthoma CE, compared to LDL (Table II). 


\section{ACKNOWLEDGMENTS}

The authors wish to thank Doctors Atkinson, Deckelbaum, and Shipley for many helpful discussions, and V. Varner and L. Askinazi for their expert technical assistance. We thank Ms. Wendy Redgrave for her expert assistance in the preparation of the manuscript.

This work was supported by National Institutes of Health grants GRS 605711, HL 18623, HL 14209, and GM 00176 from the U. S. Public Health Service, and by the C. E. Culpeper Foundation.

\section{REFERENCES}

1. Fletcher, R. F., and J. Gloster. 1964. The lipids in xanthomata. J. Clin. Invest. 43: 2104-2111.

2. Baes, H., C. M. van Gent, and C. Pries. 1968. Lipid composition of various types of xanthoma. J. Invest. Dermatol. 51: 286-293.

3. Thannhauser, S. J. 1958. Lipidoses. Grune \& Stratton, Inc., New York. 3rd edition.

4. Wilson, J. D. 1963. Studies on the origin of the lipid components of xanthomata. Circ. Res. XII: 427-478.

5. Samuel, P., W. Perl, C. M. Holtzman, N. D. Rochman, and S. Lieberman. 1972. Long term kinetics of serum and xanthoma cholesterol radioaçtivity in patients with hypercholesterolemia. J. Clin. Invest. 51: 266-278.

6. Bhattacharyya, A. K., W. E. Copnor, F. A. Mausolf, and A. E. Flatt. 1976. Turnover of xanthoma cholesterol in hyperlipoproteinemia patients. J. Lab. Clin. Med. 87: 503-518.

7. Lang, P. D., and W. Insull. 1970. Lipid droplets in atherosclerotic fatty streaks of human aorta. J. Clin. Invest. 49: 1479-1487.

8. Katz, S. S., G. G. Shipley, and D. M. Small. 1976. Physical chemistry of the lipids of human atherosclerotic lesions. Demonstration of a lesion intermediate between fatty streaks and advanced plaques. J. Clin. Invest. 58: 200-211.

9. Engelman, D. M., and G. M. Hillman. 1976. Molecular organization of the cholesteryl ester droplets in the fatty streaks of human aorta. J. Clin. Invest. 58: 997-1007.

10. Katz, S. S., D. M. Small, J. G. Brook, and R. S. Lees. 1977. The storage lipids in Tangier disease. A physical chemical study. J. Clin. Invest. 59: 1045-1054.

11. Deckelbaum, R. J., G. G.Shipley, and D. M. Small. 1977. Structure and interactions of lipids in human plasma low density lipoproteins. J. Biol. Chèm. 252: 744-754.

12. Tall, A. R., R. J. Deckelbaum, D. M. Small, and G. G. Shipley. 1977. Thermal behavior of human plasma high density lipoprotein. Biochim. Biophys. Acta. 487: 145153.
13. Tall, A. R., D. Atkinson, D. M. Small, and R. W. Mahley. 1977. Characterization of the lipoproteins of atherosclerotic swine. J. Biol. Chem. 252: 7288-7293.

14. Folch, J., M. Lees, and G. H. Sloane Stanley. 1957. A simple method for isolation and purification of total lipids from animal tissues. J. Biol. Chem. 226: 497-509.

15. Downing, D. T. 1968. Photodensitometry in the thin-layer chromatographic analysis of neutral lipids. J. Chromatogr. 38: 91-99.

16. Albrink, M. J. 1959. The microtitration of total fatty acids of serum, with notes on the estimation of triglycerides. J. Lipid Res. 1: 53-59.

17. Smith, E. B., and R. S. Slater. 1972. The microdissection of large atherosclerotic plaques to give morphologically and topographically defined fractions for analysis. Part 1 . The lipids in the isolated fractions. Atherosclerosis. 15: $37-56$.

18. Hamilton, P. B. 1963. Ion exchange chromotography of amino acids. A single column, high resolving fully automatic procedure. Anal. Chem. 35: 2055-2064.

19. Bergmann, I., and R. Loxley. 1963. Two improved and simplified methods for the spectrophotometric determination of hydroxyproline. Anal. Chem. 35: 1961-1965.

20. Hayat, M. A. 1970. Principles and technique of electron microscopy. Volume 1. Van Nostrand Reinhold Ltd. Scarborough, Ont. 96-145.

21. Venable, J. H., and R. Coggeshall. 1965. A simplified lead citrate stain for use in electron microscopy. J. Cell Biol. 25: 407-408.

22. Small, D. M. 1970. The physical state of lipids of biological importance: Cholesteryl esters, cholesterol, triglyceride. In Surface Chemistry of Biological Systems. M. Blank, editor. Plenum Publishing Corporation, New York. 55-83.

23. Tall, A. R., D. M. Small, R. J. Deckelbaum, and G. G. Shipley. 1977. Structure and thermodynamic properties of high density lipoprotein recombinants. J. Biol. Chem. 252: 4701-4711.

24. Ramachandran, G. N. 1967. Chemistry of collagen in treatise on collagen 1 . In Structure of Collagen at the Molecular Level. G. N. Ramachandran, editor. Academic Press, Inc., New York. 103-183.

25. Traub, W., and K. A. Piez. 1971. The chemistry and structure of collagen. Adv. Protein Chem. 25: 243-352.

26. McLain, P. E., and E. R. Wiley. 1972. Differential scanning calorimeter studies of the thermal transitions of collagen. J. Biol. Chem. 247: 692-697.

27. Shaw, E. H. 1963. Oriented crystallization of amides on collagen with modification of the collagen lattice. Adv. X-Ray Anal. 7: 252-255.

28. Bornstein, P. 1974. The biosynthesis of collagen. Annu. Rev. Biochem. 43: 567-603. 